\title{
Ex vivo Akt inhibition promotes the generation of potent CD19CAR T cells for adoptive immunotherapy
}

Ryan Urak, Miriam Walter, Laura Lim, ChingLam W. Wong, Lihua E. Budde, Sandra Thomas, Stephen J. Forman ${ }^{\dagger}$ and Xiuli Wang ${ }^{* \dagger}$

\begin{abstract}
Background: Insufficient persistence and effector function of chimeric antigen receptor (CAR)-redirected T cells have been challenging issues for adoptive T cell therapy. Generating potent CAR T cells is of increasing importance in the field. Studies have demonstrated the importance of the Akt pathway in the regulation of $\mathrm{T}$ cell differentiation and memory formation. We now investigate whether inhibition of Akt signaling during ex vivo expansion of CAR T cells can promote the generation of CAR T cells with enhanced antitumor activity following adoptive therapy in a murine leukemia xenograft model.
\end{abstract}

Methods: Various T cell subsets including CD8+ T cells, bulk T cells, central memory $T$ cells and naïve/memory T cells were isolated from PBMC of healthy donors, activated with CD3/CD28 beads, and transduced with a lentiviral vector encoding a second-generation CD19CAR containing a CD28 co-stimulatory domain. The transduced CD19CAR T cells were expanded in the presence of $\mathrm{LL}-2(50 \mathrm{U} / \mathrm{mL})$ and Akt inhibitor (Akti) $(1 \mu \mathrm{M})$ that were supplemented every other day. Proliferative/expansion potential, phenotypical characteristics and functionality of the propagated CD19CAR T cells were analyzed in vitro and in vivo after 17-21 day ex vivo expansion. Anti-tumor activity was evaluated after adoptive transfer of the CD19CAR T cells into CD19+ tumor-bearing immunodeficient mice. Tumor signals were monitored with biophotonic imaging, and survival rates were analyzed by the end of the experiments.

Results: We found that Akt inhibition did not compromise CD19CAR T cell proliferation and expansion in vitro, independent of the T cell subsets, as comparable CD19CAR T cell expansion was observed after culturing in the presence or absence of Akt inhibitor. Functionally, Akt inhibition did not dampen cell-mediated effector function, while Th1 cytokine production increased. With respect to phenotype, Akti-treated CD19CAR T cells expressed higher levels of CD62L and CD28 as compared to untreated CD19CAR T cells. Once adoptively transferred into CD19+ tumor-bearing mice, Akti treated CD19CAR T cells exhibited more antitumor activity than did untreated CD19CAR T cells.

Conclusions: Inhibition of Akt signaling during ex vivo priming and expansion gives rise to CD19CAR T cell populations that display comparatively higher antitumor activity.

Keywords: Akt inhibitor, CAR T cell therapy, B cell malignancies

\footnotetext{
* Correspondence: xiuwang@coh.org

${ }^{\dagger}$ Equal contributors

T cell Therapeutics Research Laboratory, Department of Hematology \&

Hematopoietic Cell Transplantation, City of Hope National Medical Center,

1500 E. Duarte Rd., Duarte, CA 91010, USA
} 


\section{Background}

Adoptive transfer of in vitro-expanded chimeric antigen receptor (CAR) $\mathrm{T}$ cells genetically modified to express tumor-targeted antigen receptors can result in dramatic regressions of B cell leukemia [1, 2]. However, insufficient persistence and effector function of CAR-redirected $\mathrm{T}$ cells in vivo has been a challenge for adoptive $\mathrm{T}$ cell therapy [3-6]. Manufacturing CAR T cells is a process that involves activation and ex vivo culture with IL-2 to facilitate CAR gene transfer and to achieve a therapeutic number of T cells. This process is also associated with decreased antitumor activity due to terminal differentiation [7].

Studies indicate that transfer of potent CAR T cells with central memory traits can enhance antitumor immunity and the curative potential of adoptive therapy for cancer [8-10]. Recent studies have highlighted the importance of the Akt and Wnt pathways in the regulation of $\mathrm{CD} 8+\mathrm{T}$ cell differentiation and memory formation [11-14]. Upon engagement of cell surface receptors such as the $\mathrm{T}$ cell receptor, co-stimulatory molecules, and cytokine receptors, the PI3K-Akt pathway is activated, resulting in downstream responses via phosphorylating a range of intracellular proteins. Akt activation is required for $\mathrm{T}$ cell activation [11]. However, studies have shown that the sustained activity of Akt progressively drives $\mathrm{T}$ cells toward terminal differentiation and diminished anti-tumor activity [11]. Crompton and van der Waart et al. have shown that reduction of Akt activation during $\mathrm{T}$ cell ex vivo expansion resulted in potent tumorinfiltrating lymphocytes (TIL) and $\mathrm{T}$ cells specific for minor histocompatibility antigens (MiHAs) on tumors $[15,16]$. We therefore hypothesized that manipulation of the magnitude of Akt activation may prevent terminal differentiation of CAR T cells as they are expanded to a therapeutic dose. To evaluate this hypothesis, we transduced and expanded CD19CAR T cells in the presence of an Akt inhibitor. We show that Akt inhibition during ex vivo expansion did not inhibit CD19CAR T cell proliferation and effector function but gave rise to less differentiated CAR T cells with high expression of CD62L and CD28 [7]. Additionally, the CAR T cells expanded in the presence of the Akt inhibitor appeared to have enhanced antitumor activity in vivo. Taken together, these findings suggest the use of pharmacologic approaches during the ex vivo expansion of CAR $T$ cells could achieve favorable attributes of CAR $\mathrm{T}$ cells for improved $\mathrm{T}$ cell therapy.

\section{Methods}

\section{Cell lines}

Unless stated otherwise, all cell lines were maintained in RPMI 1640 (Irvine Scientific) supplemented with $2 \mathrm{mM} \mathrm{L-}$ glutamine, $25 \mathrm{mM}$ HEPES, and 10\% heat-inactivated FCS (Hyclone). PBMCs were transformed with Epstein-Barr virus to generate lymphoblastoid cell lines (LCLs) as previously described [17]. To generate OKT3-expressing LCLs (LCL OKT3), allogeneic LCLs were re-suspended in nucleofection solution using the Amaxa Nucleofector kit. OKT3-2A-Hygromycin_pEK plasmid was added to $5 \mathrm{mg} / 10^{7}$ cells, the cells were electroporated using Amaxa Nucleofector I, and the resulting cells were grown in RPMI-1640 with 10\% FCS containing $0.4 \mathrm{mg} / \mathrm{mL}$ hygromycin. To generate firefly luciferase (ffluc) + GFP+ CD19+ lymphoid leukemic cells, SupB15 cells obtained from ATCC were transduced with a lentiviral vector encoding eGFP-ffluc. Initial transduction efficiency was 50\%; therefore, the GFP cells were sorted by FACS for $>98 \%$ purity (fflucGFPSupB15s).

\section{Antibodies and flow cytometry}

Human $\mathrm{T}$ cells were analyzed by flow cytometry after staining with fluorochrome-conjugated monoclonal antibodies (mAbs) to CD8 (SKI), CD62L (Dreg-56), CD45RO (UCHL1), CD45RA (L48), CD28 (CD28.2), CD3 (SK7), IFN- $\gamma$ (XMG1.2), CD107a (H4A3), KLRG1 (2 F1/KLRG1), CD57 (HNK-1), Tim3 (F38-2E2), PD1 (EH12.1), LAG3 (FAB2319C), and phosphorylated Akt (pAkt, pS473)(M8961) (BD Biosciences). Data acquisition was performed on a MACSQuant (Miltenyi Biotec) and analyzed using FCS Express, Version 3 software (De Novo Software). Telomere length analysis was performed using the flow-FISH technique with Telomere PNA Kit/FITC obtained from Dako (Dako Denmark A/S, Denmark). Biotinylated Erbitux (cetuximab) and streptavidin-PE were used to identify $\mathrm{T}$ cells that expressed truncated human EGFR (EGFRt). Anti-CD4 microbeads were purchased from Stemcell Technologies, and anti-CD14, anti-CD45RA, and anti-CD25 microbeads were purchased from Miltenyi Biotec. Proliferation capacity was determined by labeling the cells with carboxyfluorescein succinimidyl ester (CFSE) (Invitrogen).

\section{Generation of CD19 CAR T cells}

For isolation of CD8+ T cells, CD4+ T cells in PBMCs were labeled with anti-CD4 microbeads and depleted with the EasySep system (Stemcell Technologies). The freshly isolated CD4 negative cells were activated with CD3/CD28 Dynabeads (Invitrogen) and transduced the

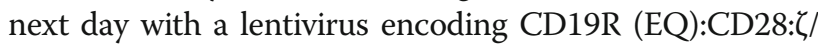
EGFRt at an MOI of 3 and expanded in the presence of $50 \mathrm{U} / \mathrm{mL}$ rhIL-2 (CellGenix) and $1 \mu \mathrm{M}$ Akt inhibitor VIII (Akti-1/2) (Merck Millipore). Cultures were then supplemented with $50 \mathrm{U} / \mathrm{mL}$ rhIL-2 (CellGenix) and Akt inhibitor every $48 \mathrm{~h}$ for 17-21 days before in vitro analysis and adoptive transfer. Transduced CD19CAR T cells without Akt inhibitor treatment were used as control, as were non-transduced mock cells from the same donor. In some experiments, bulk $\mathrm{T}$ cells, purified CD62L + CD45RO+ 
central memory $\left(\mathrm{T}_{\mathrm{CM}}\right)$ and CD62L+ naïve/memory $\mathrm{T}$ cells were engineered with CD19CAR using the selection platform that we have developed [18]. Briefly, for $\mathrm{T}_{\mathrm{CM}}$ isolation, fresh PBMC were incubated with anti-CD14, anti-CD45RA, and anti-CD25 microbeads, and the resulting labeled cells were then immediately depleted using the CliniMACS ${ }^{\text {mo }}$ depletion mode to remove CD14+ monocytes, CD25 + Treg T cells and CD45RA+ naïve $T$ cells. The resulting unlabeled negative fraction cells were then labeled with biotinylated-anti-CD62L (DREG56) $\mathrm{mAb}$ and anti-biotin microbeads. The $\mathrm{CD} 62 \mathrm{~L}+\mathrm{CD} 45 \mathrm{RO}+\mathrm{T}_{\mathrm{CM}}$ were purified with positive selection. Similarly, fresh PBMC were incubated with anti-CD14 and anti-CD25 microbeads, and the resulting labeled cells were then immediately depleted using the CliniMACS ${ }^{\text {tm }}$ to remove CD14+ monocytes and CD25 + Treg T cells. The resulting unlabeled negative fraction cells were then labeled with biotinylated-antiCD62L mAb and anti-biotin microbeads. The CD62L ${ }^{+}$ naïve/memory $\mathrm{T}$ cells were purified with positive selection.

\section{DNA constructs}

The lentivirus CAR construct was modified from the previously described CD19-specific scFvFc: $\zeta$ chimeric immunoreceptor [19] to create a second-generation vector. The CD19CAR containing a CD28z costimulatory domain carries mutations at two sites (L235E; N297Q) within the $\mathrm{CH} 2$ region on the IgG4-Fc spacers to ensure enhanced potency and persistence after adoptive transfer [20]. The lentiviral vector also expresses a truncated human epidermal growth factor receptor (huEGFRt), which includes a cetuximab (Erbitux) binding domain but excludes the EGF-ligand binding and cytoplasmic signaling domains. A T2A ribosome skip sequence links the codon-

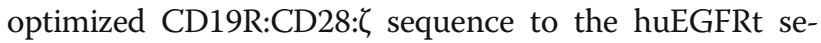
quence, resulting in coordinate expression of both CD19R:CD28: $\zeta$ and EGFRt from a single transcript [21]. The CD19CARCD28EGFRt DNA sequence (optimized by GeneArt) was then cloned into a self-inactivating (SIN) lentiviral vector, pHIV7 (gift from Jiing-Kuan Yee, Beckman Research Institute of City of Hope, Duarte, CA) (Additional file 1: Figure S1).

\section{CFSE proliferation}

Ex vivo expanded CD8 + CD19CAR $\mathrm{T}$ cells with and without Akt inhibitor treatment were labeled with $0.5 \mathrm{mM}$ CFSE and co-cultured with CD19+ LCLs as stimulator cells for 5 days in the presence of $50 \mathrm{U} / \mathrm{L}$ rhIL-2. CFSE dilution of CD3 and CAR double positive populations was determined using multicolor flow cytometry. In some experiments, CD19CAR T cells derived from $\mathrm{PBMC}$ and $\mathrm{T}_{\mathrm{CM}}$ were used for proliferation assays.

\section{Degranulation and cytokine production assays}

Ex vivo expanded CD8 + CD19CAR T cells $\left(10^{5}\right)$ with and without Akt inhibitor treatment were co-cultured with LCLs $\left(10^{5}\right)$ in medium containing Golgi plug (BD) and antibody against CD107a for six hours at $37{ }^{\circ} \mathrm{C}$. Acute myeloid leukemia KG1a cells were used as a negative stimulator and LCL OKT3 as positive stimulator. Degranulation was determined using multicolor flow cytometry. Ex vivo expanded CD8 + CD19CAR T cells with and without Akt inhibitor treatment $\left(10^{5}\right)$ were cocultured in 96-well tissue culture plates with $10^{5}$ of the indicated stimulator cells. Supernatants were harvested $18 \mathrm{~h}$ after stimulation, and cytokines were measured by a cytometric bead array using the Bio-Plex Human Cytokine Panel (Bio-Rad Laboratories) (in triplicates) according to the manufacturer's instructions.

\section{Xenograft model}

To establish a leukemic model, acute lymphoid leukemic SupB15 cells were engineered with GFP firefly luciferase (GFPffluc+), and $0.5 \times 10^{6}$ purified GFP+ cells were inoculated into six- to ten-week old NOD/Scid IL-2RyC ${ }^{\text {null }}$ (NSG) mice intravenously (i.v) on day -5 . After confirmation of the tumor engraftment, $1-2 \times 10^{6}$ expanded CD19CAR $\mathrm{T}$ cells were adoptively transferred into tumor-bearing mice intravenously. Tumor signals were monitored by Biophotonic tumor imaging.

\section{Statistical analysis}

Analyses were performed using Prism (GraphPad Software Inc.). The Mann-Whitney t- and Log-rank (Mantel-Cox) tests were used to ascertain the statistical significance of the in vivo data (tumor signals and survival). The Wilcoxon matched-pairs signed rank test (2-tailed) was used for the analysis of in vitro data except the cytokine data assumed to have a normal distribution in triplicates were analyzed with paired $t$ test. $P<0.05$ was considered statistically significant.

\section{Results \\ Akt inhibition does not compromise CD19CAR T cell proliferation and expansion}

To investigate the effects of Akt inhibition on CAR T cell expansion and function, we first sought to confirm that the Akt inhibitor (Akti) in culture can reduce phosphorylation of Akt, especially serine residue phosphorylation. Akti VIII, which selectively inhibits Akt1/Akt2 activity, has been shown to be able to induce memory $\mathrm{T}$ cell formation at a concentration of $1 \mu \mathrm{M}$ [16]. We therefore transduced purified CD8+ $\mathrm{T}$ cells and expanded CD8 + CD19CAR $T$ cells in the presence of $1 \mu \mathrm{M}$ Akti. After two to three weeks of ex vivo expansion, intracellular pAkt in the CD8 + CD19CAR T cells were analyzed with flow cytometry. We consistently 
found that $1 \mu \mathrm{M}$ Akti resulted in a trend toward modest reduction $(73.1 \pm 2.5$ to $64.0 \pm 1.5 \%)$ of phosphorylation of Akt on serine 473 in CD19CAR T cells across four different donors, but left total Akt signaling unaltered $(N=4, P=0.1)$ (Fig. 1a and b). We then investigated whether this level of reduction of Akt affects CAR T cell proliferation and expansion. Interestingly, we did not observe an effect of Akt inhibition on proliferation based on the CFSE dilution of CD8+ CD19CAR T cells (Fig. 1c), nor of bulk PBMC and $\mathrm{T}_{\mathrm{CM}}$ derived CD19CAR $\mathrm{T}$ cells $(79.1 \pm 13.6 \%$ of untreated vs. $77.6 \pm 14.9 \%$ of Akti-treated CD19CAR T cells) (Fig. 1d). Total cell growth was not compromised by inhibition of Akt signaling during 17 days of ex vivo expansion, which is the maximum days of $\mathrm{T}$ cell expansion used in our current clinical trials, indicating the intact proliferation and expansion capacity of Akti-treated CD19CAR T cells (Fig. 1e). These data were consistent with CD8+ $\mathrm{T}$ cells from multiple donors (Fig. 1f). For most adoptive $\mathrm{T}$ cell therapies, CAR $\mathrm{T}$ cell products are derived from a mixture of $\mathrm{T}$ cell populations containing both CD4+ and CD8+ T cells. We further analyzed the impact of the Akt inhibitor on the CD19CAR T cells containing both CD4+ and CD8+ subsets. Again, proliferation and expansion were not inhibited in this composition of CD19CAR T cells (Fig. 1g). Considering that the activation threshold of various T cell subsets differs [22, 23], a study of the impact of Akti on the various $\mathrm{T}$ cell subsets was performed. Purified $\mathrm{T}_{\mathrm{CM}}$ and naïve/memory $\mathrm{T}$ cells were activated, transduced and expanded in the presence of $1 \mu \mathrm{M}$ Akti. Consistently, we observed no negative effects of Akti on ex vivo expansion of all the T cell subsets tested (Fig. 1g).

\section{Akt inhibition generates CD19CAR T cell populations with memory-like characteristics}

CD3/CD28 bead stimulation and activation have been used for engineering CAR T cells to improve transduction efficiency and expansion to a therapeutic dose. However, the levels of stimulation are super-physiological, and overstimulation possibly induces terminal differentiation and functional impairment of CAR T cells [24], which could be one reason for poor antitumor response observed in some patients. Our hypothesis was that Akti would decrease the magnitude of activation and therefore preserve memory-like $\mathrm{T}$ cells with improved potential for persistence and antitumor activity after adoptive transfer. Expanded $\mathrm{T}$ cells were analyzed for memory $\mathrm{T}$ cell characteristics. After 17 days of ex vivo culture of CD8 + CD19CAR T cells, expression of CD62L was $18.2 \% \pm 7.1$ in the Akti-untreated culture and $33.9 \% \pm 11.3$ in the Akti-treated counterparts $(N=4, P=0.1)$. CD62L + CAR+ double positive cells were $34.9 \% \pm 9.7$ and $58.0 \% \pm 9.7$ $(N=4, P=0.2)$ in the Akti-untreated culture and in the Akti-treated counterparts, respectively (Fig. 2a and b).
Consistently, when gated CAR+ cells were analyzed, Akti-treated CD8 + CD19CAR T cells co-express higher levels of CD62L and CD28 as compared to the untreated CD19CAR T cells $(50.3 \% \pm 3.7$ vs. $10.3 \% \pm 4.8)$ $(N=4, P=0.1)$ (Fig. 2c and d), suggesting that Aktiexpanded CD8 + CD19CAR T cells appear less differentiated and possess a memory phenotype. To further understand the levels of senescence and exhaustion of the CD8 + CD19CAR T cells, we analyzed expression of KLRG1, CD57, Tim3, PD1 and LAG3, which are known to be the hallmarks of exhaustion. Our data support that Akti did not increase the senescence of CD8 + CD19CAR T cells (Fig. 2e). We also measured and compared the relative telomere lengths. In line with the findings that Akti had no effects on proliferative capacity and senescence of the CD8 + CD19CAR, Akti-treated, purified CD8 + CD19CAR T cells derived from three donors maintained relatively equal telomere length (Fig. 2f) as compared to untreated CD8 + CD19CAR T cells $(N=3, P=0.3)$. Although purified $\mathrm{T}_{\mathrm{CM}}$ and naïve/memory $\mathrm{T}$ cells originally express high levels of CD62L (80\%), after activation/lentiviral transduction and ex vivo expansion, CD62L expression decreased to $40-50 \%$. Consistently, Akti addition preferentially retained CD62L expression on the cultured cells (Fig. 3a) to $50-80 \%$. The same results were observed when unselected bulk $\mathrm{T}$ cells were tested. These studies demonstrate that manipulation of levels of Akt activation could prevent differentiation derived from CD3/CD28 activation/expansion and promote enhanced central memory $\mathrm{T}$ cell subsets. Consistent with engineered CD19CAR T cells from purified CD8+ T cells, CD28 + CD62L + CAR + T cells derived from bulk PBMC, $\mathrm{T}_{\mathrm{CM}}$ and naïve/memory $\mathrm{T}$ cells are significantly higher in the Akti treated conditions as compared to untreated counterparts $(N=6, P=0.03)$ (Fig. 3b). However, exhaustive features remain the same, indicating that Akti prevents CAR T cell differentiation and does not induce exhaustion of CAR T cells (Fig. 3c).

\section{Akt inhibition does not dampen cell-mediated cytotoxicity but increases cytokine production}

Akt activation appears to be essential for the development of effector function in activated CD8+ T cells [25] and is required for efficient adoptive therapy. To assess this functionality, we analyzed Akti-treated CD8 + CD19CAR T-cells for degranulation ability upon co-culture with different targets. We found equivalent levels of CD107a + cells in CD19CAR and Akti-treated CD19CAR T cells upon CD19+ tumor stimulation ( $24.9 \pm 15$ vs. $27.8 \pm 13.4 \%$, respectively) (Fig. 4a and b). Maximum degranulation remained the same as indicated by the degranulation ability after stimulation with LCL OKT3, which engages the entire $\mathrm{T}$ cell 

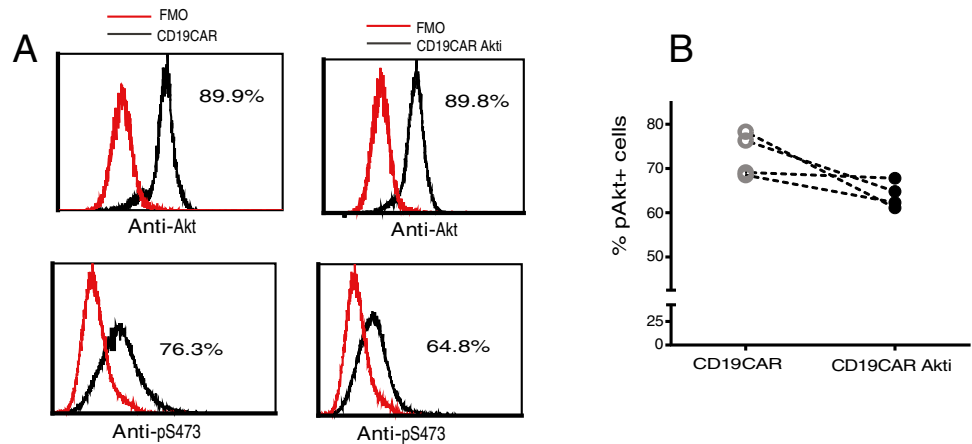

C
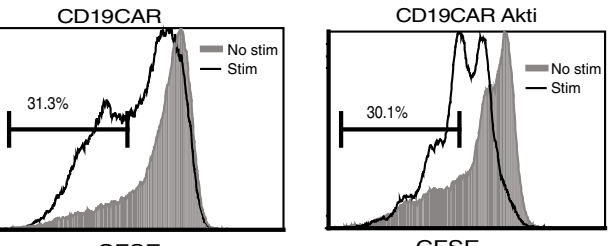

D

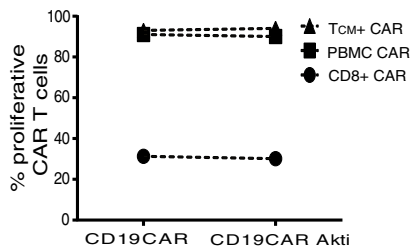

E
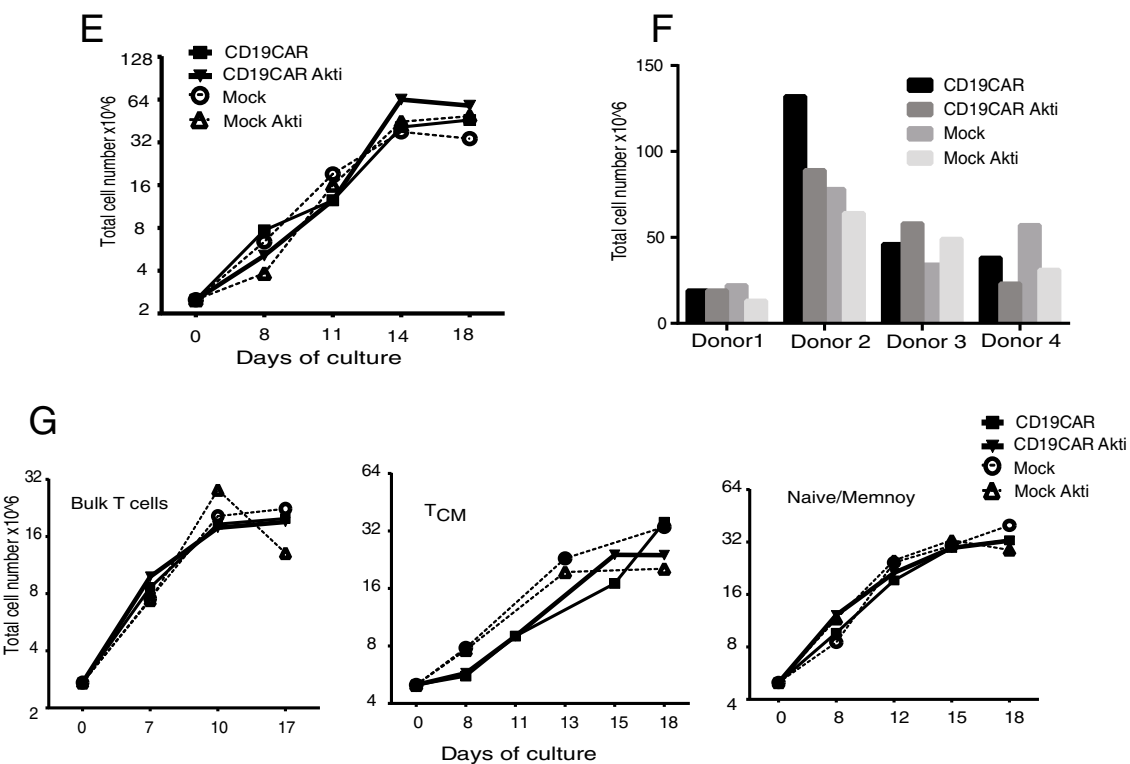

Fig. 1 Akt inhibition does not compromise CD19CAR T cell proliferation and expansion. CD8+ T cells in PBMC from healthy donors were isolated by CD4+ T cell depletion following anti-CD4 microbeads labeling and magnetic selection with the EasySep system. The freshly isolated CD4 negative cells were activated with CD3/CD28 Dynabeads and transduced the next day with CD19R (EQ):CD28:Z/EGFRt lentivirus at an MOl of 3, then expanded. The cultures were supplemented with $50 \mathrm{U} / \mathrm{mL}$ rhlL-2 and $1 \mu \mathrm{M}$ Akt inhibitor every $48 \mathrm{~h}$ for $17-21$ days before in vitro analysis. Transduced CD19CAR T cells without Akt inhibitor treatment were used as control. a Expanded CD8 + CD19CAR T cells were harvested and stained intracellularly with antibodies against phosphorylated Akt pS473 and total Akt. Fluorescence minus one (FMO) are depicted in red histograms. Histograms are of gated CD19CAR+ T cells. $\mathbf{b}$ Percentages of phosphorylated Akt positive cells from four different donors are presented. $\mathbf{c}$ Expanded CD8 + CD19 CAR T cells were labeled with $0.5 \mathrm{mM}$ CFSE and then co-cultured with CD19+ LCLs as stimulators for 5 days in the presence of 50U/L rhlL-2. CFSE dilution of gated CD3+ and CAR+ double positive populations was determined using multicolor flow cytometry. Percentages of CFSE negative cells over non-stimulated cells are presented. d Percentages of CFSE negative CAR T cells derived from different T cell subsets are depicted. e CD8+ T cells were transduced with lentivirus encoding CD19CAR vector and expanded in a medium containing 50U/L rhIL2, in the presence and absence of $1 \mu \mathrm{M}$ Akt inhibitor. Viable cell numbers were determined by Guava ViaCount at the indicated time points. $\mathbf{f}$ Data on day 17 from four different donors are presented. $\mathbf{g}$ Bulk T cells, purified TCM and purified naïve/memory T cells were transduced with lentivirus encoding second generation CD19CAR vector and expanded in a medium containing 50U/L rhlL2, in the presence and absence of $1 \mu \mathrm{M}$ Akt inhibitor. Viable cell numbers were determined by Guava ViaCount at the indicated time points. Mock $T$ cells from the same donor were used as controls

receptor (TCR), suggesting that the tumor-specific and intrinsic capacity of effector function was not affected by Akt inhibition. Cytokine production, another benchmark of effector function, was analyzed. Cytokines that were released into the supernatant after stimulator and responder co-culture were measured by cytometric bead array. 
A
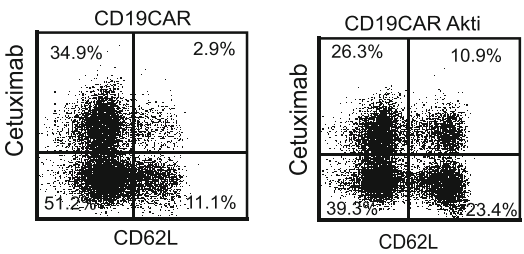

C
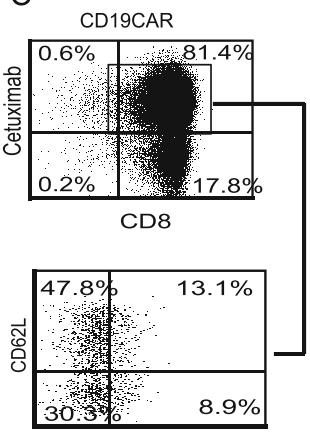

CD28

$E$

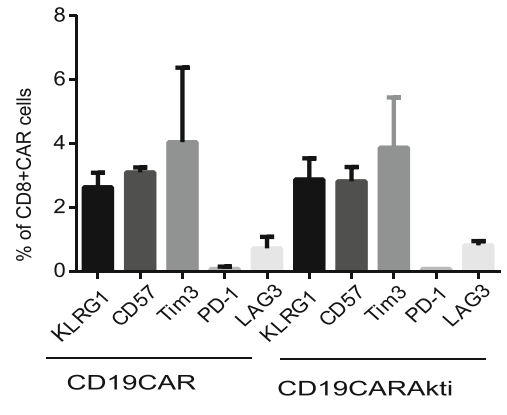

B
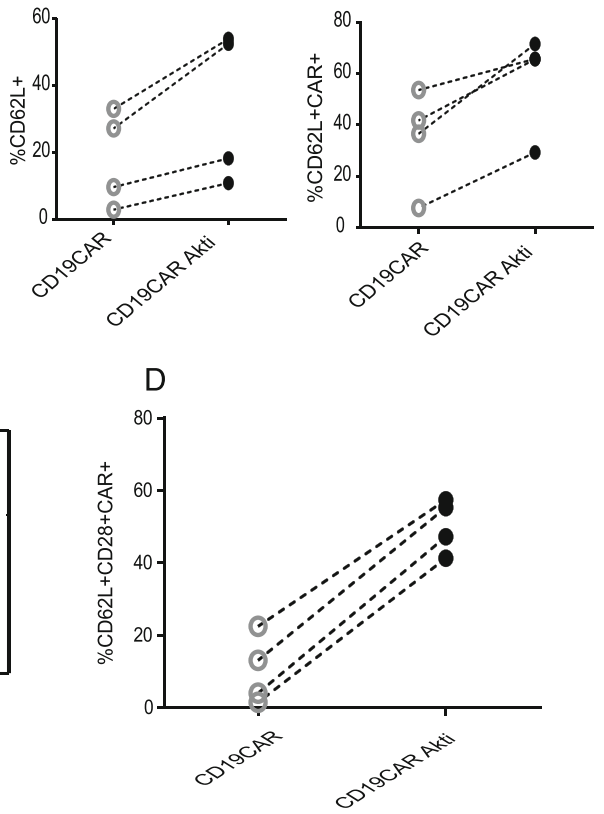

$\mathrm{F}$

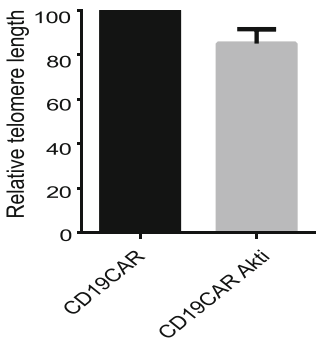

Fig. 2 Akt inhibition generates CD8 + CD19CAR T cell populations with memory-like characteristics. CD8 + CD19CAR T cells that had been cultured in the presence and absence of $1 \mu \mathrm{M}$ Akti were stained with biotinylated Erbitux (cetuximab), followed by streptavidin-PE for CAR detection and antibodies against CD8, CD62L, CD28, KLRG1, CD57, Tim3, PD1, and LAG3. a Percentages of CD62L+ and CAR + CD62L+ double positive cells are depicted on the basis of the gating of isotype-stained cells. $\mathbf{b}$ Percentages of CD62L+ and CAR + CD62L+ double positive cells from four different donors are presented. c Expression and percentages of CD62L and CD28 after gating on CAR+ cells are presented. $\mathbf{d}$ Percentages of CD62L + CD28 + CAR+ cells after gating on CAR+ cells. Data from four different donors are presented. e Mean percentages of immunoreactive cells + SEM from 4 different donors are presented. f In vitro expanded CD8 + CD19CAR+ T cells were collected. Relative telomere length of T cells was determined with Telomere PNA detection kit and normalized against 1301 cell line as control. Means + SEMs of duplicates from three different donors are depicted. RTL $=$ (mean FL1 sample cells with probe-mean FL1 sample cells without probe) $\times$ DNA index of control cells $\times 100 /$ (mean FL1 control cells with probe-mean FL1 control cells without probe) $\times$ DNA index of sample cells

Significantly higher levels of Th1 cytokines IFN $\gamma(P<0.05)$ and GM-CSF $(P<0.05)$ were produced by $\mathrm{CD} 8+$ CD19CAR T cells treated with Akti (Fig. 4c) upon CD19 antigen (LCL) stimulation, indicating a population with greater effector function. However, Th2 cytokines such as IL-10, IL-4, and IL-6 that hamper the induction of effective of $\mathrm{T}$ cell response were not significantly increased upon CD19 antigen stimulation (Fig. 4d).

\section{Akti-expanded CD19CAR T-cells appeared to exhibit greater anti-tumor efficacy and expansion in vivo}

The principal aim of the study was to determine whether Akti promotes the generation of CAR T cells with enhanced antitumor activity. Building on the memory-like phenotypic traits and improved cytokine production, we anticipated that Akti-expanded CD8 + CD19CAR T cells would possess enhanced anti-tumor 
A

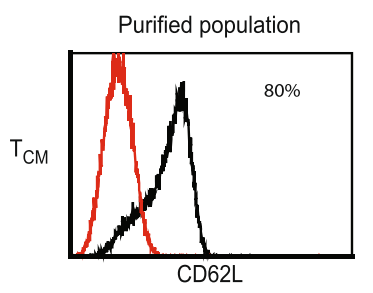

Purified population

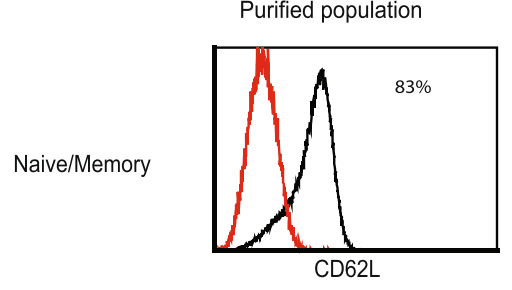

T cells

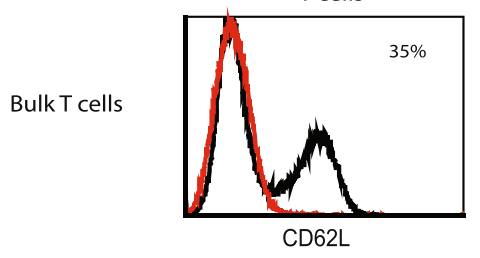

B

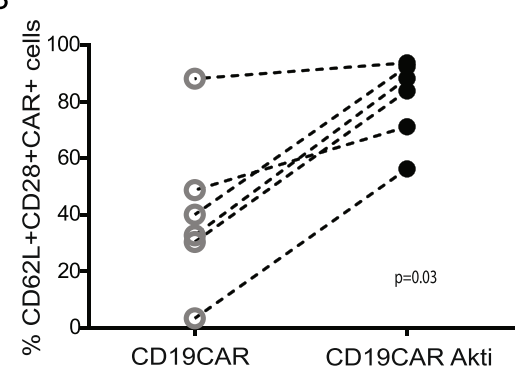

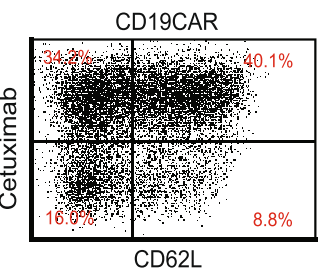
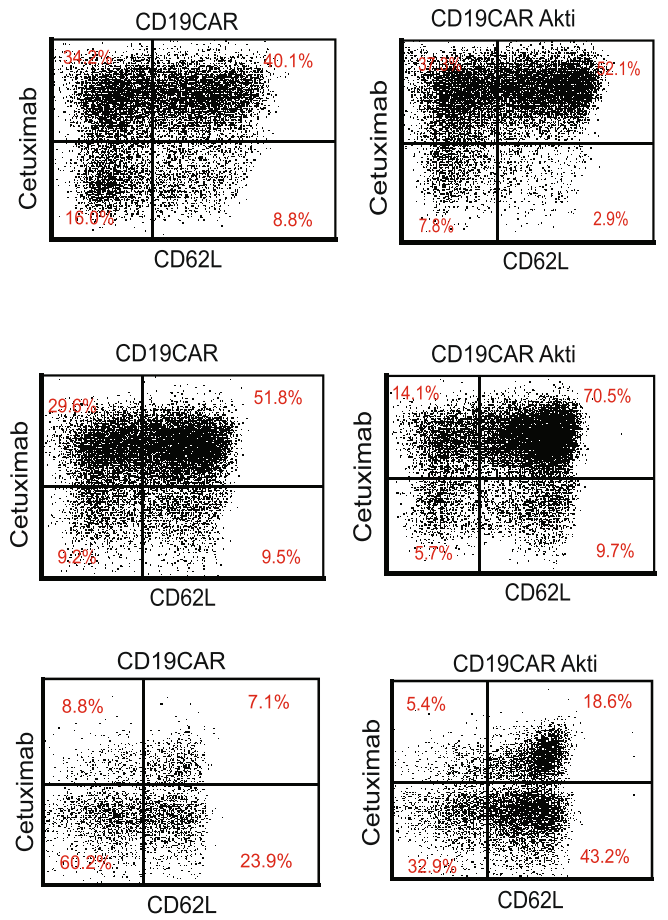

C

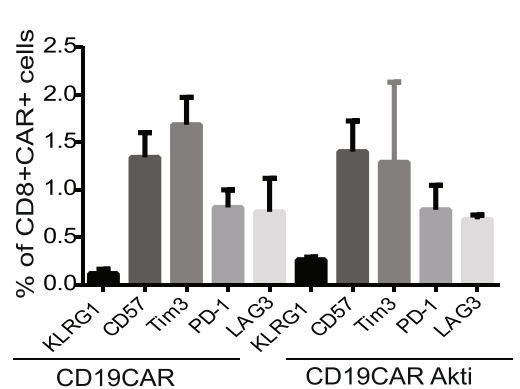

Fig. 3 Akt inhibition promotes the generation of memory CD19CAR T cells from different T cell subsets. a Bulk T cells, purified TCM, and purified naïve/memory $T$ cells were transduced with lentivirus encoding second generation CD19CAR vector and expanded in a medium containing 50U/L rhIL2, in the presence and absence of $1 \mu \mathrm{M}$ Akt inhibitor for 17-21 days. Resultant CD19CAR T cells were stained with biotinylated Erbitux (cetuximab), followed by streptavidin-PE for CAR detection and antibodies against CD62L. Percentages of CAR + CD62L+ cells are depicted on the basis of the gating of isotype-stained cells. b Percentages of CD62L + CD28+ T cells after gating on CAR + CD8+ from six lines derived from two different donors are presented. c Mean percentages of immunoreactive cells + SEMs from six lines of two different donors are presented

activity once transferred into B cell leukemia tumorbearing mice. To test the antitumor activity, we delivered a suboptimal $\left(2 \times 10^{6}\right)$ dose of CD $8+$ CD19CAR $\mathrm{T}$-cells intravenously into mice following systemic inoculation of human CD19+ leukemic cells. Tumor burden in the mice was monitored on a weekly basis, and Kaplan-Meier survival analysis was performed. Consistent with the in vitro observation, untreated CD8 + CD19CAR T cells induced transient tumor regression, but tumors re-progressed rapidly. In contrast, mice treated with an equal number of Akti-treated CD8 + CD19CAR exhibited significantly higher antitumor activity $(p=0.02)$ with significantly prolonged survival $(p=0.008)$ (Fig. 5). One mouse had no evidence of tumor 100 days from inoculation. We also tested the anti-tumor activity of bulk CD19 CAR-T cells containing CD4 T cells and CD8 T cells that were expanded in the presence of Akti and compared them with non-treated cells having the same proportion of CD4, CD8, and CAR subsets. We again observed what appeared to be more tumor regression when mice were treated with Akti-treated CD19CAR T cells than untreated counterpart (Fig. 6a, b, and c). Furthermore, 40 days post CAR T cell transfer, higher levels of human T cells and CAR T cells were detected in the mice that received Akti-treated CD19CAR T cells than that in 

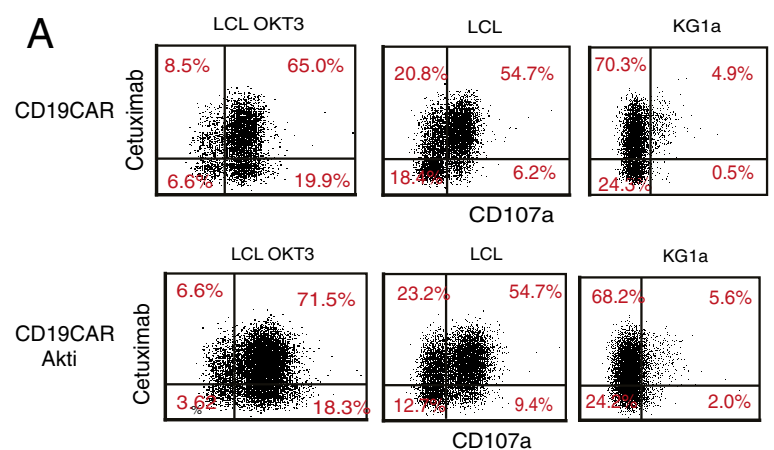

C
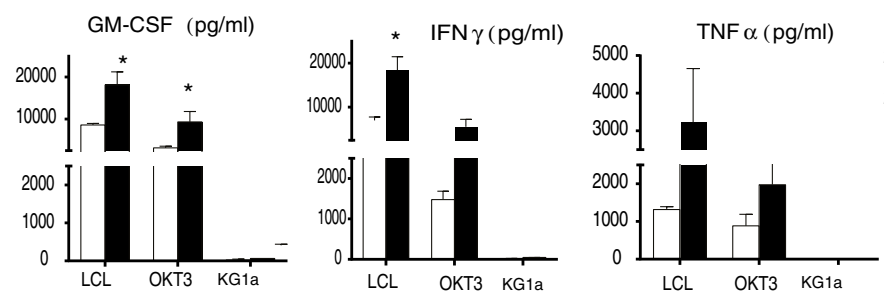

$\mathrm{D}$
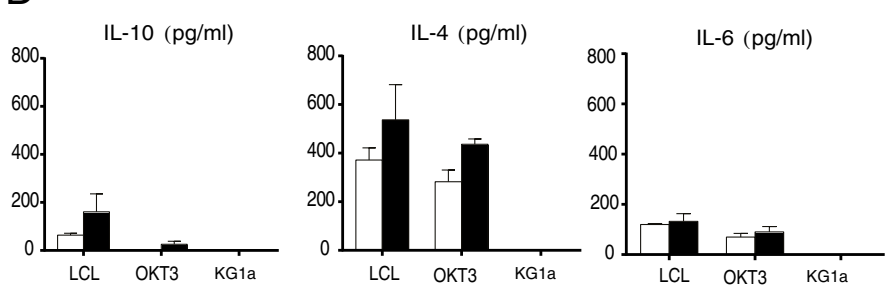

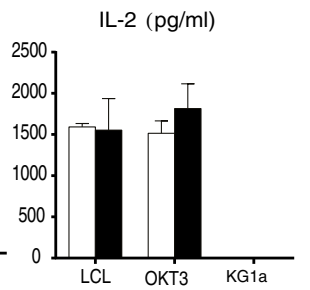

B
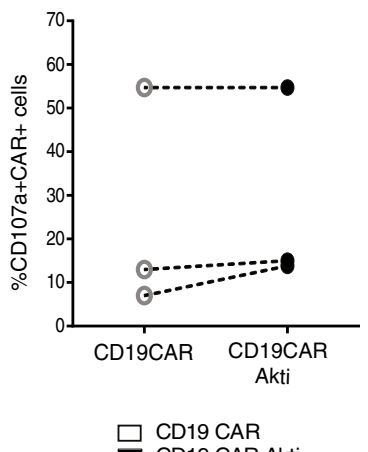

CD19 CAR Akti

${ }^{*}<0.05$

Fig. 4 Akt inhibition does not dampen cell-mediated cytotoxicity but increases cytokine production of CD8 + CD19CAR T cells. After 21 days of in vitro expansion, a CD8 + CD19CAR T-cells with and without Akt inhibitor treatment were co-cultured with LCLs at a 1:1 ratio in medium containing Golgi plug and CD107a for six hours at $37^{\circ} \mathrm{C}$. KG1a cells were used as negative stimulator and LCL OKT3 as positive stimulator. Degranulation was determined using multicolor flow cytometry. Percentages of CAR +CD107a + T cells are presented. $\mathbf{b}$ Accumulated data from three different donors are presented. $\mathbf{c ~ C D 8}+$ CD19CAR T cells with and without Akt inhibitor treatment were co-cultured with LCLs at a 1:1 ratio in medium for eighteen hours at $37^{\circ} \mathrm{C}$. Supernatants were harvested and cytokines were measured by a cytometric bead array. Means + SEMs of triplicates are depicted. KG1a cells were used as a negative stimulator and LCLOKT3 as positive stimulator

the mice that received non-Akti-treated counterparts, although the results are not statistically significant (Fig. 6d). Percentages of CAR T cells in the harvested blood were similar to the input cells ( 30\%) (Fig. 6e), suggesting that Akti-treated CD19CAR T cells were proportionately expanded in vivo following adoptive transfer. To demonstrate Akti has similar impacts on different T cell subsets, propagated CD19CAR $\mathrm{T}$ cells derived from purified $\mathrm{T}_{\mathrm{CM}}$ and naïve/memory $\mathrm{T}$ cells in the presence and absence of Akti were tested for their antitumor activity in vivo. Consistently, Akti-treated CD19CAR $\mathrm{T}_{\mathrm{CM}}$ (Fig. 7a and b) and naïve/memory T cells (Fig. 7c and d) exhibited greater antitumor activity as compared with their untreated counterparts even though the CD4+ CAR $\mathrm{T}$ cells are dominant in the $\mathrm{T}_{\mathrm{CM}}$ populations. To rule out the xeno-reactivity of infused Akti-treated CD19CAR T cells, mouse body weight, an indicator of GVHD, was measured. We observed no evidence of GVHD such as loss of body weight (Additional file 2: Figure S2) and hair loss, on day 28, when the highest active antitumor activity occurred.

\section{Discussion}

Effective $\mathrm{T}$ cell therapy against cancer is dependent on the formation of long-lived memory $\mathrm{T}$ cells with the ability to self-renew and differentiate into potent effector cells. These goals have been approached by various means, including using defined central memory $\mathrm{T}$ cells as a starting population for gene modification, optimizing CAR design, and supplementing with cytokine cocktails during ex vivo 


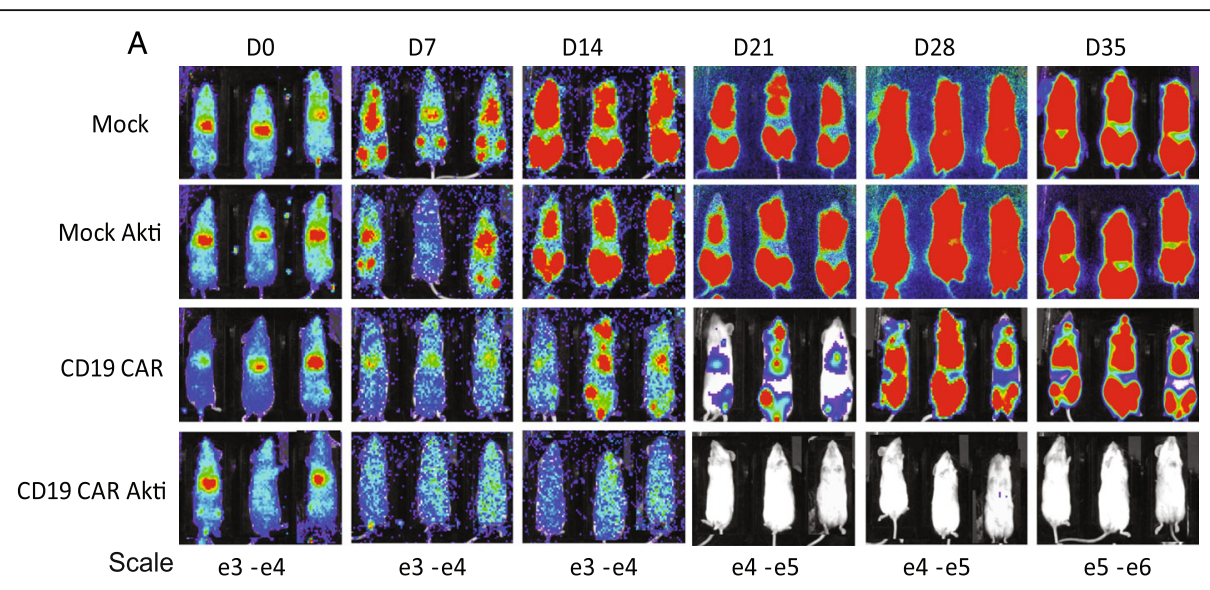

B

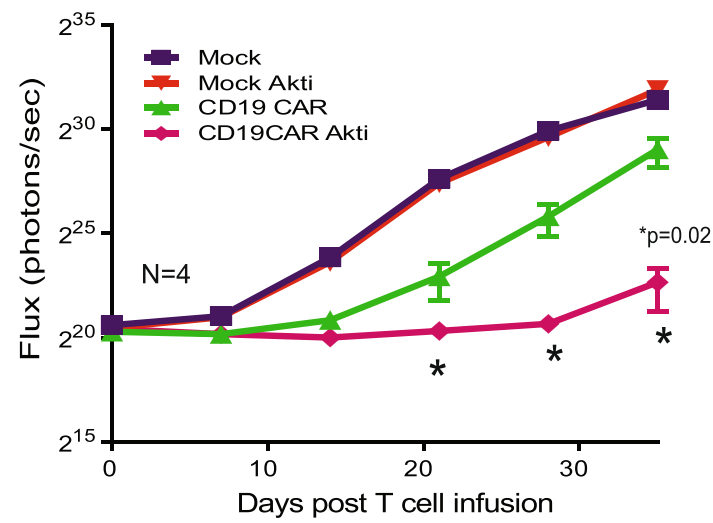

C

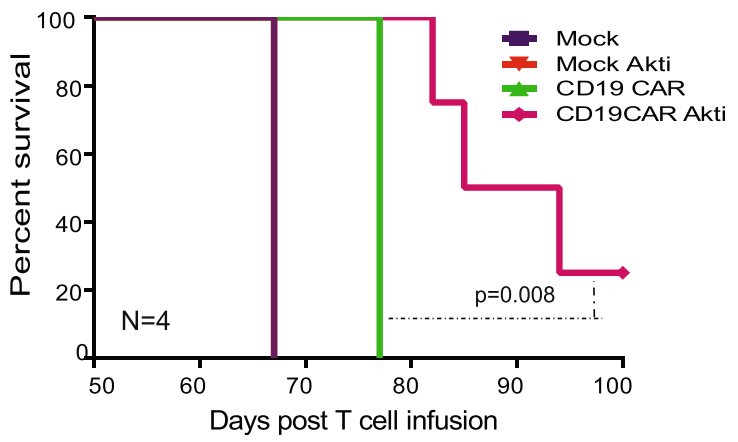

Fig. 5 Akti-treated CD8 + CD19CAR T cells exhibit increased anti-tumor efficacy in vivo. $0.5 \times 10^{6}$ acute lymphoid leukemic SupB15 cells engineered with GFP firefly luciferase (GFPffluc+) were inoculated into NSG mice intravenously (i.v) on day -5. After confirmation of tumor engraftment, $2 \times 10^{6}$ expanded CD8 + CD19CAR+ T cells were adoptively transferred into tumor-bearing mice intravenously. Non-transduced mock cells from the same donor were used as controls. a Tumor signals were monitored by biophotonic tumor imaging and $\mathbf{b}$ the bioluminescence signal was measured as total photon flux normalized for exposure time and surface area and expressed in units of photons (p) per second per $\mathrm{cm}^{2}$ per steradian (sr). c Kaplan-Meier survival curve. $N=4$ mice per group

expansion [8, 18, 26, 27]. All of these strategies are feasible, but validation before translating to a clinical platform is costly and time-consuming. There are several pharmacologic candidates capable of driving $\mathrm{T}$ cells toward the memory phenotype, such as those activating the $\mathrm{Wnt} / \beta$-catenin pathway [14] and inhibiting m-TOR mediated protein translation [28]. However, the concentration required for significant inhibition of $\mathrm{T}$ cell differentiation might also lead to immunosuppressive and anti-proliferative activity $[29,30]$. Our data support that addition of Akti at $1 \mu \mathrm{M}$ during ex vivo expansion did not interfere with CD8 + CD19 CAR T cell proliferation and expansion. The same results were also observed in different $\mathrm{T}$ cell subsets such as bulk $\mathrm{T}$ cell, $\mathrm{T}_{\mathrm{CM}}$, and naïve/memory-derived CD19CAR T cells, indicating that this is a general feature of the Akti on $\mathrm{T}$ 

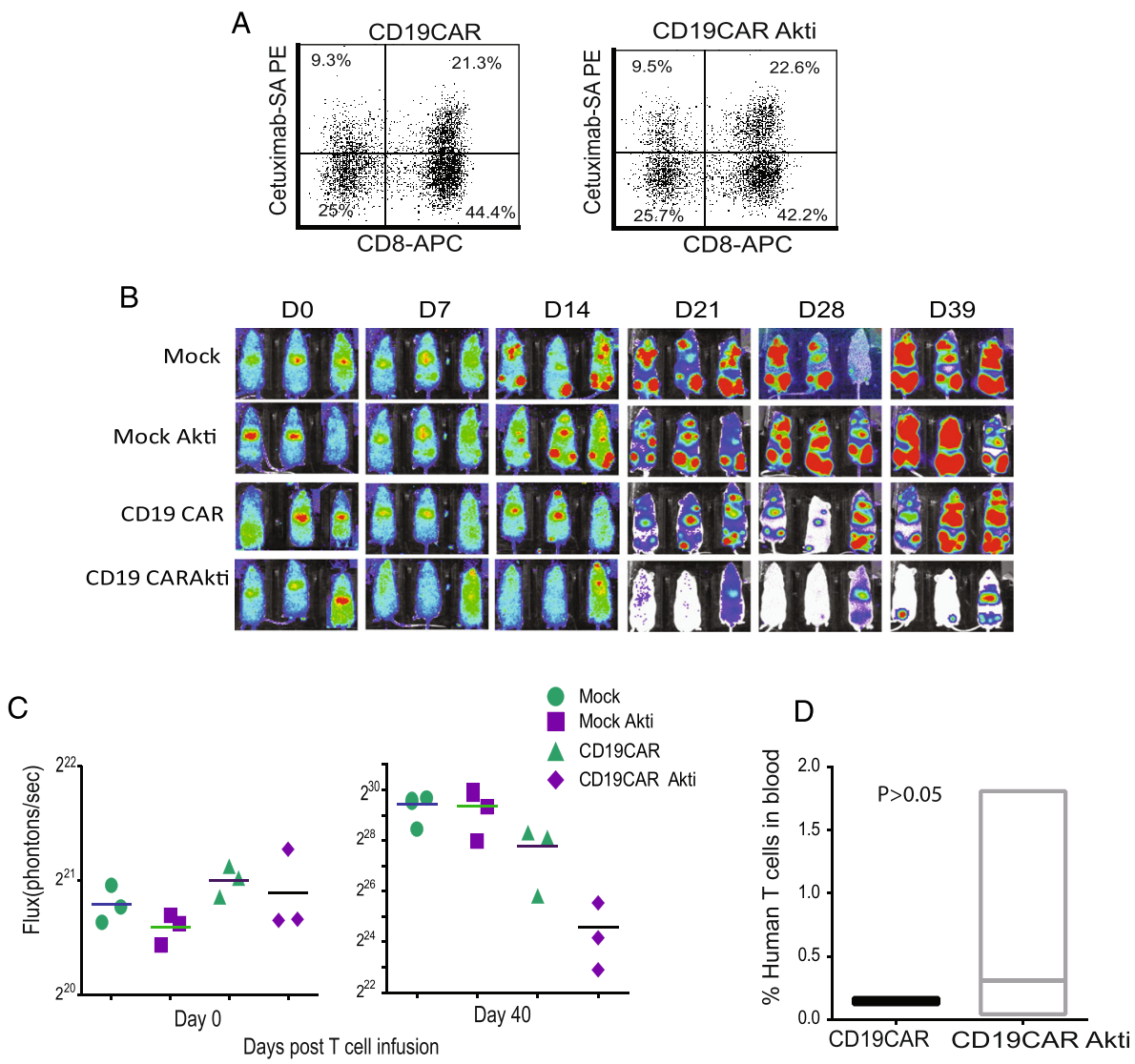

$\mathrm{E}$

CD19CAR
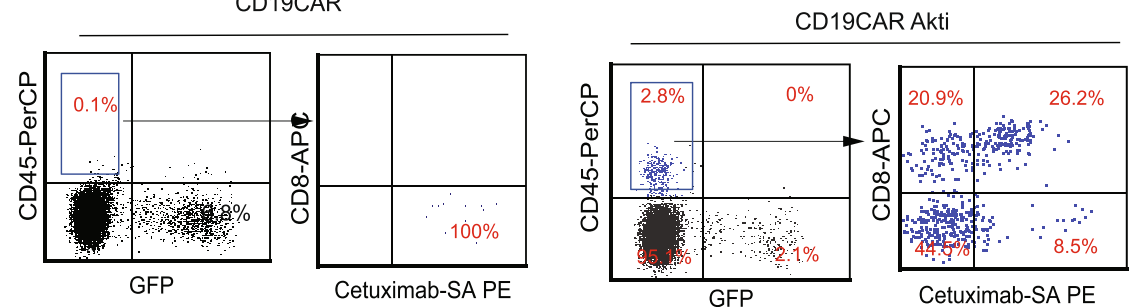

Fig. 6 Akti-treated CD4 + CD19CAR+ and CD8 + CD19CAR T cells exhibit increased anti-tumor efficacy and persistence in vivo. PBMC from healthy donors were activated with CD3/CD28 Dynabeads and transduced the next day with CD19R (EQ):CD28:C/EGFRt lentivirus at an MOI of 3. The cultures were supplemented with $50 \mathrm{U} / \mathrm{mL}$ rhlL-2 and Akt inhibitor every $48 \mathrm{~h}$ for 21 days. Transduced CD19CAR T cells without Akt inhibitor treatment were used as control. Non-transduced mock T cells were used as another type of control. a Percentages of CD8 and CAR positive cells in the input population are presented. b Acute lymphoid leukemic $0.5 \times 10^{6} \mathrm{SupB} 15$ cells engineered with GFPffluc were inoculated into NSG mice ( $N=3$ mice per group) intravenously (i.v) on day -5 . After confirmation of the tumor engraftment, $1 \times 10^{6}$ expanded CD19CAR+ T cells were adoptively transferred into tumor-bearing mice intravenously. Tumor signals were monitored by Biophotonic tumor imaging and $\mathbf{c}$ the bioluminescence signal was measured as total photon flux normalized for exposure time and surface area and expressed in units of photons $(p)$ per second per $\mathrm{cm}^{2}$ per steradian (sr). d Forty days post adoptive transfer, mice were euthanized, and blood were analyzed after staining with antibodies against human CD45, CD8 and cetuximab for CAR detection. Mean percentages of human CD45 positive and GFP (tumor) negative cells from three mice are presented. e CD8+ and CAR T cells gated on CD45 positive human T cells are depicted

cell proliferation and expansion and therefore can be used for clinical manufacturing of therapeutic doses of CAR $T$ cell products without the restriction of starting $\mathrm{T}$ cell populations. Our data indicated that Akti at $1 \mu \mathrm{M}$ resulted in modest reduction (12\%) of phosphorylated Akt in the CAR T cells. A $\sim 5$-fold increase in concentration is anticipated to further reduce phosphorylated Akti at Ser
473 [31]. However, careful titration of Akti during CAR T cell generation is necessary to maximize potency without suppressing $\mathrm{T}$ cell expansion and function. The optimal concentration of Akti may additionally vary among the various $T$ cell subsets as starting population. Efficient CAR $\mathrm{T}$ cell therapy relies on potent effector function and in vivo persistence following adoptive transfer. Our studies 
A

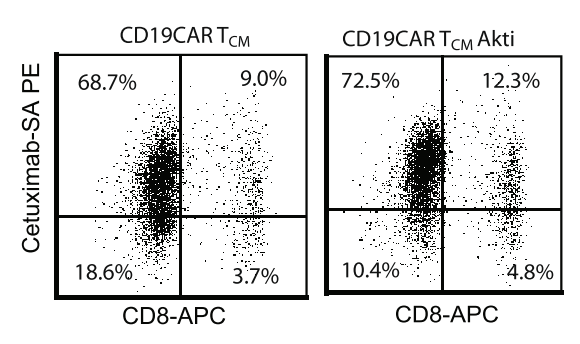

C

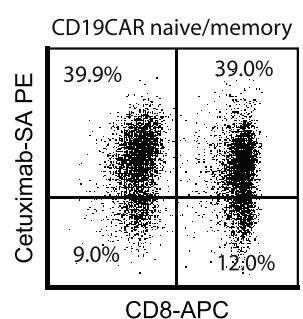

B

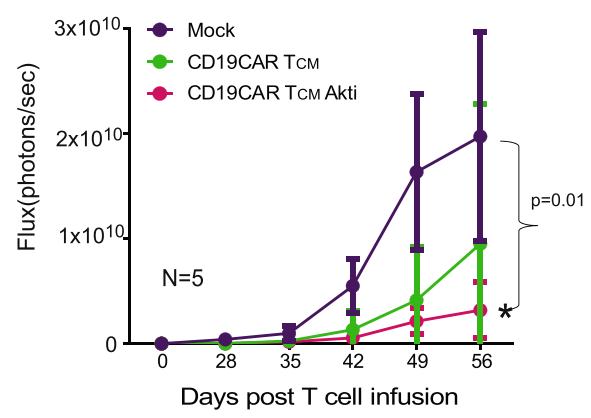

D

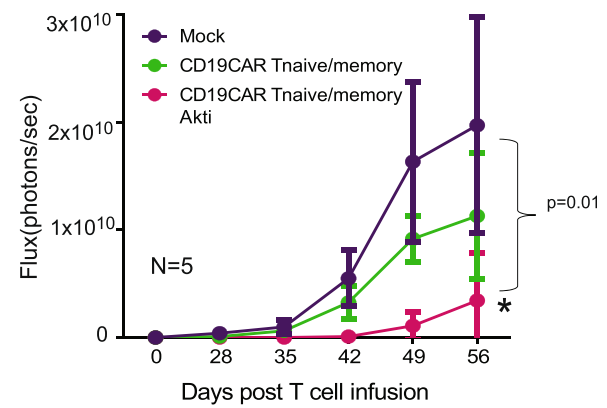

Fig. 7 Akti-treated CD19CAR $T_{C M}+$ and CD19CAR naïve/memory T cells exhibit greater anti-tumor efficacy in vivo. $T_{C M}$ and naive/memory T cells from healthy donors were isolated and activated with CD3/CD28 Dynabeads and transduced the next day with CD19R (EQ):CD28:Z/EGFRt lentivirus at an $\mathrm{MOI}$ of 3. The cultures were supplemented with $50 \mathrm{U} / \mathrm{mL}$ rhlL-2 and Akt inhibitor every $48 \mathrm{~h}$ for 21 days. Transduced CD19CAR T cells without Akt inhibitor treatment were used as control. Non-transduced mock T cells were used as another type of control. Acute lymphoid leukemic $0.5 \times 10^{6}$ SupB15 cells engineered with GFPffluc were inoculated into NSG mice ( $N=5$ mice per group) intravenously (i.v) on day -5 . After confirmation of the tumor engraftment, $1 \times 10^{6}$ expanded CD19CAR+ T cells were adoptively transferred into tumor-bearing mice intravenously. Tumor signals were monitored by Biophotonic tumor imaging and the bioluminescence signal was measured as total photon flux normalized for exposure time and surface area and expressed in units of photons (p) per second per $\mathrm{cm}^{2}$ per steradian (sr). a Percentages of CD8 and CAR positive cells in the input CD19CAR $T_{C M}$ population are presented. b Tumor signals at different time points are presented. $\mathbf{c}$ Percentages of CD8 and CAR positive cells in the input CD19CAR naïve/memory population are presented. $\mathbf{d}$ Tumor signals at different time points are presented

demonstrated that manipulation of levels of Akt activation enhanced the antigen-specific effector function of CD19CAR T cells as indicated by elevated Th1 cytokines such as IFNY and GM-CSF while preventing differentiation. Studies have shown that $\mathrm{T}$ cells with memory characteristics positively correlate with in vivo persistence and antitumor activity post adoptive transfer [32]. Despite no statistically significant differences as a result of variation among donors and a limited number of donors, our studies consistently demonstrated that Akti-treated CD19CAR T cells exhibited higher expression levels of CD62L and CD28 without expression of exhaustion phenotypes such as KLRG1, which are the traits required for efficient anti-tumor activity following adoptive transfer [33]. In further support, there did not appear to be a difference in telomere length between cultures with or without Akti. Upon transfer into CD19 tumor-bearing mice, Akti-treated CD8 + CD19CAR T cells efficiently inhibited tumor growth and induced long-term survival as a result of improved antitumor activity and/or expansion. The role of the Akt signaling pathway in CD4+ cells is more complicated and poorly understood than in CD8+ cells because of the interplay of regulatory versus conventional $\mathrm{CD} 4+\mathrm{T}$ cells that contain different $\mathrm{CD} 4+\mathrm{T}$ cell subsets. However, more tumor reduction in the mice treated with an Aktiinhibited mixture of CD4 + CD19CAR and CD8 + CD19 CAR $\mathrm{T}$ cells indicates the minor impact of Akti-treated Tregs on the overall therapeutic effects. This validates the use of Akti when both CD4+ and CD8+ T cells are included in the starting population for CAR $\mathrm{T}$ cell engineering and manufacturing. We also found that Aktitreated CAR T cells did not induce alloreactivity, an important safety consideration. Built on the pre-clinical studies $[8-10,34]$ demonstrating that $\mathrm{T}_{\mathrm{CM}}$ and naive/ memory $\mathrm{T}$ cells possess characteristics that correlate with improved anti-tumor activity, current clinical trials have developed a clinical platform for purification, transduction, and expansion of CD19CAR $\mathrm{T}_{\mathrm{CM}}$ for adoptive immunotherapy, with the goal of long-term CAR T cell disease surveillance [35]. Our current studies demonstrate that Akti does not inhibit $\mathrm{T}_{\mathrm{CM}}$ and naïve/ 
memory-derived CD19CAR $\mathrm{T}$ cell expansion but promotes the generation of memory CD19CAR $\mathrm{T}$ cells with greater antitumor activity and supports the use of Akti for further improved CAR T cell therapy in these advanced platforms. The underlying mechanisms may be related to changes in metabolic and transcriptional signatures characteristic of long-lived memory $\mathrm{T}$ cells that are reprogrammed by Akt inhibition [16, 25, 36]. Meanwhile, our data support that Akt inhibition has no impact on replicative senescence based on the lack of changes in relative telomere length and exhaustive features.

\section{Conclusion}

Our data suggest that inhibition of Akt signaling during ex vivo priming, expansion, and culturing gives rise to a CD19CAR T cell population that possesses increased antitumor activity. These findings suggest that therapeutic modulation of Akt might be a strategy to augment antitumor immunity for adoptive CAR T cell therapy, which could easily be transitioned into the clinic with the availability of a pharmaceutical grade Akt inhibitor.

\section{Additional files}

Additional file 1: Figure S1. Schematic of the CD19CAR-T2A-EGFRt The CD19R:zeta DNA sequence (optimized by GeneArt) contains the chimeric antigen receptor (CAR) sequence consisting of the $V_{H}$ and $V_{L}$ gene segments (sCFV) of the CD19-specific FMC63 monoclonal antibody (mAb); IgG4 hinge containing the 2 point mutations, L235E and N297Q in the $\mathrm{CH} 2$ portion (CD19R(EQ)); the CD28 costimulatory domain; signaling domains CD3 zeta; and the self-cleaving T2A and the truncated EGFR (EGFRt) sequences. (EPS $1663 \mathrm{~kb}$ )

Additional file 2: Figure S2. CD19CAR T cells expanded in the presence of Akti did not induce allo-reactivity in xenograft model. T cell subsets were isolated and activated with CD3/CD28 Dynabeads and transduced the next day with CD19R (EQ):CD28:zeta/EGFRt lentivirus at an MOI of 3. The cultures were supplemented with $50 \mathrm{U} / \mathrm{mL}$ rhlL-2 and Akt inhibitor every $48 \mathrm{~h}$ for 21 days. Acute lymphoid leukemic $0.5 \times 10^{6}$ SupB15 cells engineered with GFPffluc were inoculated into NSG mice intravenously (i.v) on day -5. After confirmation of the tumor engraftment, $1 \times 10^{6}$ expanded CD19CAR+ T cells were adoptively transferred into tumor-bearing mice intravenously. Transduced CD19CAR T cells without Akt inhibitor treatment were used as control. Non-transduced mock T cells were used as another type of control. Body weight was measured on day 28 post T cell infusion, when the most active antitumor activity occurred in CD19CAR Akti treated mice. Means \pm SEMs are presented. Number of mice in each group is presented on the top of the bar. (EPS $1490 \mathrm{~kb}$ )

\section{Abbreviations}

Akti: Akt inhibitor; CAR: Chimeric antigen receptor; CFSE: Carboxyfluorescein succinimidyl ester; EGFRt: Truncated human EGFR; GFPffluc: Green fluorescence firefly luciferase; LCL: Lymphoblastoid cell lines; $T_{C M}$ : Central memory $T$ cells

\section{Acknowledgments}

The authors thank James Sanchez for assistance in generating the manuscripts and Saul Priceman for critical reading of the manuscript.

\section{Funding}

This study was supported by the Tim Nesvig Lymphoma Research Fund, the Skirball Foundation and two grants from the National Cancer Institute of the National Institutes of Health: the City of Hope Lymphoma SPORE (P50 CA107399) and the City of Hope Cancer Center Support Grant (P30 CA33572).
Availability of data and materials

Data are available upon request for academic researchers.

\section{Authors' contributions}

XW and SJF designed and directed the study, analyzed and organized the data, and wrote the manuscript. RU, MW, LL and CWW performed experimental work in mice and immune assays. ST and LEB reviewed the manuscript. All authors were involved with manuscript revision and all authors approved the final version.

\section{Competing interests}

The authors declare that they have no competing interests.

Ethics approval and consent to participate

PBMC products were obtained from healthy consented donors under protocols approved by the City of Hope Institutional Review Board. All mouse experiments were approved by the City of Hope Institutional Animal Care and Use Committee.

Received: 2 June 2016 Accepted: 17 February 2017

Published online: 21 March 2017

\section{References}

1. Kalos M, Levine BL, Porter DL, Katz S, Grupp SA, Bagg A, June CH. T cells with chimeric antigen receptors have potent antitumor effects and can establish memory in patients with advanced leukemia. Sci Transl Med. 2011; 3:95ra73.

2. Brentjens RJ, Davila ML, Riviere I, Park J, Wang X, Cowell LG, Bartido S, Stefanski J, Taylor C, Olszewska M, et al. CD19-targeted t cells rapidly induce molecular remissions in adults with chemotherapy-refractory acute lymphoblastic leukemia. Sci Transl Med. 2013;5:177ra138.

3. Pule MA, Savoldo B, Myers GD, Rossig C, Russell HV, Dotti G, Huls MH, Liu E, Gee AP, Mei Z, et al. Virus-specific T cells engineered to coexpress tumorspecific receptors: persistence and antitumor activity in individuals with neuroblastoma. Nat Med. 2008;14:1264-70.

4. Rosenberg SA, Yang JC, Sherry RM, Kammula US, Hughes MS, Phan GQ, Citrin DE, Restifo NP, Robbins PF, Wunderlich JR, et al. Durable complete responses in heavily pretreated patients with metastatic melanoma using T-cell transfer immunotherapy. Clin Cancer Res. 2011;17:4550-7.

5. Dudley ME, Yang JC, Sherry R, Hughes MS, Royal R, Kammula U, Robbins PF, Huang J, Citrin DE, Leitman SF, et al. Adoptive cell therapy for patients with metastatic melanoma: evaluation of intensive myeloablative chemoradiation preparative regimens. J Clin Oncol. 2008;26:5233-9.

6. Uttenthal BJ, Chua I, Morris EC, Stauss HJ. Challenges in T cell receptor gene therapy. J Gene Med. 2012;14:386-99.

7. Gattinoni L, Klebanoff CA, Palmer DC, Wrzesinski C, Kerstann K, Yu Z, Finkelstein SE, Theoret MR, Rosenberg SA, Restifo NP. Acquisition of full effector function in vitro paradoxically impairs the in vivo antitumor efficacy of adoptively transferred CD8+ T cells. J Clin Invest. 2005;115:1616-26.

8. Wang X, Berger C, Wong CW, Forman SJ, Riddell SR, Jensen MC. Engraftment of human central memory-derived effector CD8+ T cells in immunodeficient mice. Blood. 2011;117:1888-98.

9. Berger C, Jensen MC, Lansdorp PM, Gough M, Elliott C, Riddell SR. Adoptive transfer of effector CD8 T cells derived from central memory cells establishes persistent T cell memory in primates. J Clin Invest. 2008; 118:294-305.

10. Gattinoni L, Lugli E, Ji Y, Pos Z, Paulos CM, Quigley MF, Almeida JR, Gostick E, Yu Z, Carpenito C, et al. A human memory T cell subset with stem cell-like properties. Nat Med. 2011;17:1290-7.

11. Kim EH, Suresh M. Role of PI3K/Akt signaling in memory CD8 T cell differentiation. Front Immunol. 2013;4:20.

12. Yoo JK, Cho JH, Lee SW, Sung YC. IL-12 provides proliferation and survival signals to murine CD4+ T cells through phosphatidylinositol 3-kinase/Akt signaling pathway. J Immunol. 2002;169:3637-43.

13. Kim EH, Sullivan JA, Plisch EH, Tejera MM, Jatzek A, Choi KY, Suresh M. Signal integration by Akt regulates CD8 T cell effector and memory differentiation. J Immunol. 2012;188:4305-14.

14. Gattinoni L, Zhong XS, Palmer DC, Ji Y, Hinrichs CS, Yu Z, Wrzesinski C, Boni A, Cassard L, Garvin LM, et al. Wnt signaling arrests effector T cell differentiation and generates CD8+ memory stem cells. Nat Med. 2009;15:808-13. 
15. van der Waart AB, van de Weem NM, Maas F, Kramer CS, Kester MG Falkenburg JH, Schaap N, Jansen JH, van der Voort R, Gattinoni L, et al. Inhibition of Akt signaling promotes the generation of superior tumorreactive T cells for adoptive immunotherapy. Blood. 2014;124:3490-500.

16. Crompton JG, Sukumar M, Roychoudhuri R, Clever D, Gros A, Eil RL, Tran E, Hanada K, Yu Z, Palmer DC, et al. Akt inhibition enhances expansion of potent tumor-specific lymphocytes with memory cell characteristics. Cancer Res. 2015;75:296-305.

17. Pelloquin F, Lamelin JP, Lenoir GM. Human B lymphocytes immortalization by Epstein-Barr virus in the presence of cyclosporin A. In Vitro Cell Dev Biol. 1986;22:689-94.

18. Wang X, Naranjo A, Brown CE, Bautista C, Wong CW, Chang WC, Aguilar B, Ostberg JR, Riddell SR, Forman SJ, Jensen MC. Phenotypic and functional attributes of lentivirus-modified CD19-specific human CD8+ central memory T cells manufactured at clinical scale. J Immunother. 2012;35:689-701.

19. Kowolik CM, Topp MS, Gonzalez S, Pfeiffer T, Olivares S, Gonzalez N, Smith DD, Forman SJ, Jensen MC, Cooper LJ. CD28 costimulation provided through a CD19-specific chimeric antigen receptor enhances in vivo persistence and antitumor efficacy of adoptively transferred T cells. Cancer Res. 2006;66:10995-1004

20. Jonnalagadda M, Mardiros A, Urak R, Wang X, Hoffman LJ, Bernanke A Chang WC, Bretzlaff W, Starr R, Priceman S, et al. Chimeric antigen receptors with mutated lgG4 Fc spacer avoid fc receptor binding and improve T cell persistence and antitumor efficacy. Mol Ther. 2015;23:757-68.

21. Wang X, Chang WC, Wong CW, Colcher D, Sherman M, Ostberg JR, Forman SJ, Riddell SR, Jensen MC. A transgene-encoded cell surface polypeptide for selection, in vivo tracking, and ablation of engineered cells. Blood. 2011;118: 1255-63.

22. Kimachi K, Sugie K, Grey HM. Effector T cells have a lower ligand affinity threshold for activation than naive T cells. Int Immunol. 2003;15:885-92.

23. Berard M, Tough DF. Qualitative differences between naive and memory $T$ cells. Immunology. 2002;106:127-38.

24. Li Y, Kurlander RJ. Comparison of anti-CD3 and anti-CD28-coated beads with soluble anti-CD3 for expanding human T cells: differing impact on CD8 T cell phenotype and responsiveness to restimulation. J Transl Med. 2010;8:104.

25. Macintyre AN, Finlay D, Preston G, Sinclair LV, Waugh CM, Tamas P, Feijoo C, Okkenhaug K, Cantrell DA. Protein kinase B controls transcriptional programs that direct cytotoxic T cell fate but is dispensable for T cell metabolism. Immunity. 2011;34:224-36.

26. Wang $X$, Wong CW, Urak R, Mardiros A, Budde LE, Chang WC, Thomas SH, Brown CE, Rosa C, Diamond DJ, et al. CMVpp65 vaccine enhances the antitumor efficacy of adoptively transferred CD19-redirected CMV-specific T cells. Clin Cancer Res. 2015;21:2993-3002.

27. Cieri N, Camisa B, Cocchiarella F, Forcato M, Oliveira G, Provasi E, Bondanza A, Bordignon C, Peccatori J, Ciceri F, et al. IL-7 and IL-15 instruct the generation of human memory stem T cells from naive precursors. Blood. 2013;121:573-84.

28. Waickman AT, Powell JD. mTOR, metabolism, and the regulation of T-cell differentiation and function. Immunol Rev. 2012;249:43-58.

29. Nikolaeva N, Bemelman FJ, Yong SL, van Lier RA, ten Berge IJ. Rapamycin does not induce anergy but inhibits expansion and differentiation of alloreactive human T cells. Transplantation. 2006;81:445-54.

30. Coenen JJ, Koenen HJ, van Rijssen E, Hilbrands LB, Joosten I. Rapamycin, and not cyclosporin A, preserves the highly suppressive CD27+ subset of human CD4 + CD25+ regulatory T cells. Blood. 2006;107:1018-23.

31. Calleja V, Laguerre M, Parker PJ, Larijani B. Role of a novel PH-kinase domain interface in PKB/Akt regulation: structural mechanism for allosteric inhibition. PLoS Biol. 2009;7:e17.

32. Yang S, Ji Y, Gattinoni L, Zhang L, Yu Z, Restifo NP, Rosenberg SA, Morgan RA. Modulating the differentiation status of ex vivo-cultured anti-tumor T cells using cytokine cocktails. Cancer Immunol Immunother 2013;62:727-36.

33. Wang X, Wong CW, Urak R, Taus E, Aguilar B, Chang WC, Mardiros A, Budde $L E$, Brown $C E$, Berger $C$, et al. Comparison of naive and central memory derived CD8 effector cell engraftment fitness and function following adoptive transfer. Oncoimmunology. 2016;5:e1072671.

34. Hinrichs CS, Borman ZA, Gattinoni L, Yu Z, Burns WR, Huang J, Klebanoff CA, Johnson LA, Kerkar SP, Yang S, et al. Human effector CD8+ T cells derived from naive rather than memory subsets possess superior traits for adoptive immunotherapy. Blood. 2011;117:808-14.
35. Turtle CJ, Hanafi LA, Berger C, Gooley TA, Cherian S, Hudecek M, Sommermeyer D, Melville K, Pender B, Budiarto TM, et al. CD19 CAR-T cells of defined CD4+:CD8+ composition in adult B cell ALL patients. J Clin Invest. 2016;126:2123-38.

36. Finlay DK. mTORC1 regulates CD8+ T-cell glucose metabolism and function independently of PI3K and PKB. Biochem Soc Trans. 2013;41:681-6.

\section{Submit your next manuscript to BioMed Central and we will help you at every step:}

- We accept pre-submission inquiries

- Our selector tool helps you to find the most relevant journal

- We provide round the clock customer support

- Convenient online submission

- Thorough peer review

- Inclusion in PubMed and all major indexing services

- Maximum visibility for your research

Submit your manuscript at www.biomedcentral.com/submit
Biomed Central 